\title{
THE USE OF 3-PLANE SCHROTH GYMNASTYCS IN THE TREATMENT OF GRADE 2 SCOLIOSIS
}

\author{
Khudetskyy I., Antonova-Rafi Y., Pshenichna V. \\ National Technical University \\ "Igor Sikorsky Kyiv Polytechnic Institute", Kyiv, Ukraine \\ https://doi.org/10.35339/ic.7.4.194-199
}

\begin{abstract}
Background. Scoliosis is defined as deformity of the spinal column and torso in three dimensions. The cause of scoliosis remains unknown. Therefore, such scoliosis is called idiopathic. Adolescent idiopathic scoliosis is one of the most common structural deformities of the spine in adolescents, which aggravates during an active growth. Physical rehabilitation plays an important role in the system of complex conservative treatment of scoliotic disease. The most effective conservative treatment is 3-plane gymnastics according to the method of C. Schroth and brace therapy according to Abbott-Cheneau principle. Objective. Improving a comprehensive program of physical rehabilitation for adolescents with scoliotic disease of the second degree by Schroth method and determining its effectiveness. Methods. We examined 14 patients aged 11-15 years with scoliotic disease of the second degree. These patients were divided into 2 groups: main and control ( 7 persons in each, respectively). In patients of the main group the complex treatment of scoliosis that included Schroth's method in combination with massage and brace therapy was used. In the control group comprehensive rehabilitation treatment included restorative and preventive measures according to the generally accepted program. Results. The use of Schroth technique in a comprehensive physical rehabilitation program better reduced Cobb's angle of deviation of the spine, increased strength endurance of the back and abdominal muscles, improved formation of the muscular corset, largely eliminated cosmetic defects. Conclusion. Schroth's technique had a positive effect on Cobb's angle and other parameters in adolescent girls with a grade 2 scoliosis. The multicomponent Schroth technique, which includes passive correction, self-stretching and corrected breathing creates conditions for is necessary to be widely implemented in clinical practice.

Keywords. Schroth's gymnastics, scoliosis, scoliotic disease, orthopedic devices, Cobb's angle.
\end{abstract}

\section{Introduction}

At present medical check-ups of preschool and school children frequently reveal children with posture disorders. Increase in the number of children and adolescents with the consequences of scoliosis progression is one of the main concerns of pediatric orthopedics. Scoliotic disease causes both physical and psychological problems. Therefore, it is important to distinguish pathology of posture and scoliosis as early as possible [7].

Scoliotic disease is a genetically caused problem of the human musculoskeletal system characterized by multiplanar deformity of the

Corresponding Author:

Viktoria Pshenichna, student

of the National Technical University

"Igor Sikorsky Kyiv Polytechnic Institute", Kyiv, Ukraine, Kyiv, Ukraine.

E-mail:Vika20011998@ukr.net spinal column and chest, accompanied by dysfunction of the organs and systems of the body. Scoliosis is not only medical, but also a complex social problem that requires a comprehensive approach [1].

Scoliosis prevalence in the world varies from 3.2 to $20.0 \%$ of the general population and from $2-5$ to $13.3 \%$ in pediatric one. Over the recent 20 years, the number of patients with scoliosis has increased from 6.4 to $17.0 \%$ [15].

Despite of the high frequency, the diagnosis of scoliosis in adolescents is problematic as there is no pain or other inconvenience until a pronounced cosmetic defect develops [3].

The diagnostic procedure usually includes history taking, visual examination, special tests to determine the mobility of the spinal column, evaluation of Cobb's angle of the spinal column deviation. 
Among the numerous methods of determining the curvature angle, the most widespread is Cobb's method, based on determining the angle formed by the two end vertebrae of the curvature arc [14]. For this purpose two lines are drawn of the $\mathrm{x}$-ray film, in parallel with the planes of the neutral vertebrae and a wide intervertebral space. At the point of intersection of these lines the angle of scoliosis is measured. At small curvatures the additional angle between the perpendiculars to these lines is determined (fig. 1).

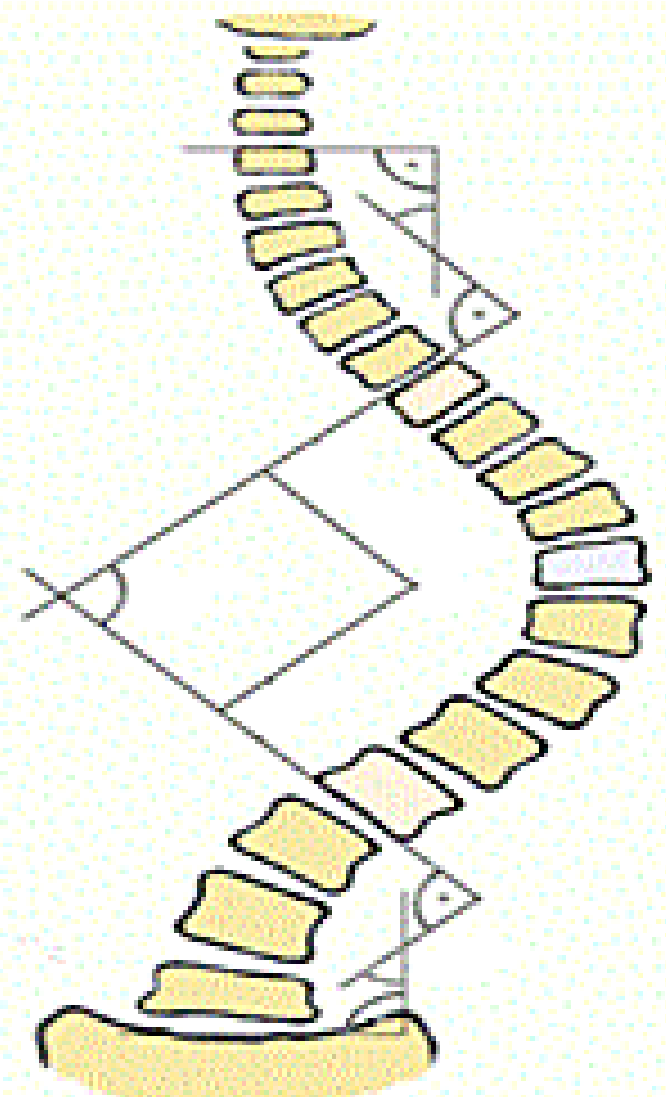

Fig. 1. Determining the angle by Cobb's method [9]

Based on Riesser's test, the prognosis of scoliotic deformity is made, as well as the possibility of wearing a back brace is assessed. This test can be performed using x-ray films (fig. 2). The principle of this test consists in the fact that ossification of the iliac bones begins at the anterior upper edge and moves to the end. The iliac crest is divided into 4 parts. The degree of maturity is determined by the number of squares that have been ossified. For example, grade 3 according to Riesser means that $75 \%$ of the iliac crest has been ossified. Grade 4 means that all four parts have been ossified. Grade 5 according to Riesser means that all four parts have been ossified and merged with the iliac bone. When a child reaches

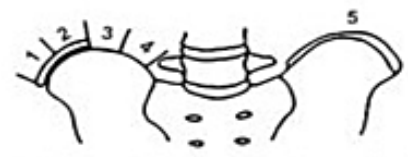

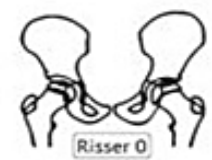
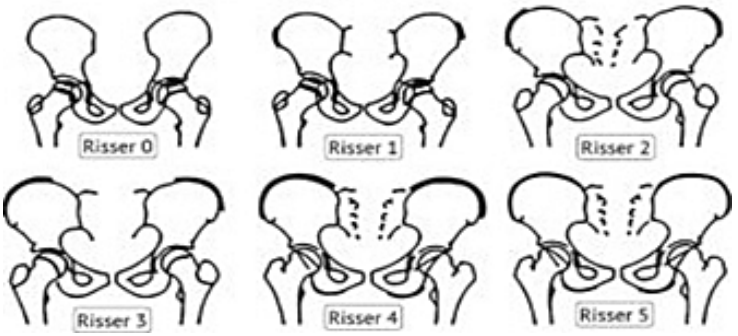

Fig. 2. Scheme for determining the bone age. Riesser's test [6]

ossification of grade 5 , it makes no sense to wear a back brace, because the growth zones are closed and the growth of the spinal column and its mobility have stopped [12].

The most popular and effective method of physical rehabilitation of patients with scoliosis in European countries is 3-plane anti-scoliotic gymnastics according to Schroth and brace therapy by the principle of Abbott-Cheneau. Such programs are currently used in hospitals of Germany and Spain and include courses lasting for 3-5 weeks 4-6 hours a day [12].

Schroth's method is a conservative gymnastics based on 3-plane correction with alignment of the torso in the typical for each type of scoliosis position and correct breathing. The goal is to develop the internal muscles of the chest and ribs in order to change the shape of the upper torso and correct any abnormalities of the spinal column.

Proper breathing is the main part of Schroth's gymnastics as in scoliotic patients the thorax participates in breathing asymmetrically. It is due to the spinal column rotation and the thorax deformity. Thus, intercostal spaces from the side of the concavity are diminished and o the opposite side they are enlarged, that is why with every inhalation the greater volume of air comes in lungs from the convex side, and less from the concave one. This is one of the causes of rib hump formation and falling in of the ribs on the opposite side. The correct breathing is directed opposite to the curvature side, i.e. inhalation is done by the falling in zones of the thorax [14].

Another main feature is development of a new "correction position". All exercises in the program are mostly static, providing different loads on different muscles depending on the type of curvature and severity of scoliotic disease. Their main goal is to stabilize the corrected position in all three planes of the spinal column and to form a muscular core [14]. 
However, prolonged wearing of the brace relaxes the paravertebral muscles by maintaining the body with the brace, and therefore performing exercises for the back muscles is necessary to strengthen them, give them the right shape and keep them in the corrected position.

\section{Purpose, subjects and methods:}

2.1. The purpose of the work was to determine the most effective rehabilitation program for adolescents with grade 2 scoliosis.

\subsection{Subjects \& Methods}

14 female patients aged $10-15$ years with grade 2 scoliosis were examined. The examination program included generally recommended diagnostic methods $[2,4,5,11,13]$ :

- functional examination (determination of the static strength endurance of the muscles of the back, abdomen and oblique muscles of the abdomen in the child);

- clinical and instrumental examination (visual inspection and palpation, measurement of the height and length of the lower extremities, measurement of vertebral torsion, level of the upper arms, shoulders, waist triangles, lumbar lordosis, pelvic level, feet. Vital capacity of the lungs and some cardiovascular system parameters were also assessed.

Several forms of scoliosis were diagnosed in the examined subjects:

- right thoracic - left lumbar scoliosis $(\mathrm{n}=5)$,

- right cervical-thoracic - left lumbar scoliosis $(\mathrm{n}=2)$,

- right thoracolumbar scoliosis $(\mathrm{n}=3)$,

- left-cervical-thoracic - right thoracolumbar scoliosis $(n=2)$,

- left thoracolumbar scoliosis ( $\mathrm{n}=2$ ).

The original physical rehabilitation program was developed based on the forms and methods of kinesiotherapy, focused on both tonic effect and targeted preventive and corrective effects. The following methodological principles were used in the program:

1. The degree and type of disorders in the spatial organization of the child's body, as well as the degree of scoliotic deformity were taken into account.

2. The character of the exercises, dosage of physical activity, sequence of exercises, starting positions, intensity corresponded to the general health, physical development and fitness level of the patient.

3. Each training was based on the principle of comprehensive influence on the body and all muscle groups. Special corrective exercises were alternated with static exercises, self-stretching exercises, exercises with objects and on balancing platforms and balls to improve proprioception.

4. Principles of gradualness and consistency were used both to teach the correct posture (for each type of deformity) as well as correction of the posture disorder and in dosing each exercise and the complex of exercises as a whole.

5. When selecting the exercises, the emphasis was placed to strengthening (training) the weakened, overstretched muscles and relaxation, stretching of the muscles with relatively high tone against a background of uniform training of other muscle groups.

6. Each session necessarily included an exercise to relax tense muscles.

7. Performing respiratory cycles (inhalations and exhalations in the fallen in and convex areas) was necessary to expand the intercostal spaces and reduce them, respectively, on the opposite side.

8. Great attention was paid to maintaining a positive emotional background during the lessons which contributed to the effectiveness of the correct posture skills, correcting scoliotic deformity and decreased the program efficacy.

To compare the effectiveness of the developed rehabilitation program, the examined patients were divided into 2 groups: the main group (MG) (girls aged 11-15 years, $n=7$ ) and the control group (CG) (girls aged 10-14 years, $n=7$ ).

Physical rehabilitation program for children from the main group included the methods of the original program (namely exercises for 3-plane correction of scoliosis by the method of C.Schroth in combination with massage and brace therapy).

Children from the control group were treated with restorative and preventive measures according to the generally accepted program of scoliotic deformity correction. Duration and intensity of the programs matched to each other. The comparative characteristics of the exercises included in the rehabilitation program of the main and control groups are presented in table 1.

The investigation was carried out according to the standard principles of bioethics.

The findings of the study were evaluated by the methods of mathematical statistics. Mathematical processing of numerical data was carried out using the methods of variation statistics. The significance of the difference was assessed using Mann-Whitney test. Differences not exceeding the probability level $p<0.05$ at a given number of degrees of freedom were considered statistically significant. Statistica 7.0 application program was used for mathematical processing of the numerical data. 
Table 1

Comparative characteristics of exercises

\begin{tabular}{|l|l|}
\hline \multicolumn{1}{|c|}{ Main group } & \multicolumn{1}{|c|}{ Control group } \\
\hline $\begin{array}{l}\text { 1. Static exercises in the position of "correction" with } \\
\text { correctly selected inhalations and exhalations, performed } \\
\text { in different starting positions, w ith objects and without } \\
\text { objects }\end{array}$ & $\begin{array}{l}\text { 1. Exercises for formation of skills of correct posture: } \\
\text { started from adoption of the correct posture near the } \\
\text { wall and with each lesson expanded to perform } \\
\text { exercises in different positions with the correct posture }\end{array}$ \\
\hline $\begin{array}{l}\text { 2. Static exercises aimed at strengthening the muscles of } \\
\text { the back, abdomen and lateral muscles of the torso. The } \\
\text { number of repetitions for each exercise was different and } \\
\text { was selected individually depending on the functional } \\
\text { capabilities of the body }\end{array}$ & \\
\hline $\begin{array}{l}\text { 3. Exercises for relaxation, stretching of spasmodic and } \\
\text { tense muscles. Exercises to coordinate and stabilize the } \\
\text { spine in the correct position }\end{array}$ & $\begin{array}{l}\text { 3. Exercises to relax the muscles of the back (namely } \\
\text { the muscular embankments), the lateral muscles of the } \\
\text { torso (concave side), the muscles of the legs and arms }\end{array}$ \\
\hline
\end{tabular}

\section{Conflict of interests}

The authors of the article declare no conflict of interest.

\section{Results \& discussion}

3-plane correction exercises according to the method of C.Schroth improved the body position and evenly distributed the load to al muscles due to adhering to the characteristic individual "posture of correction", increasing strength endurance of the muscles of the back and abdomen, i.e. formation of strong muscular core, which is a guarantee of effective stabilization of the scoliotic process (fig. 3-5). This also stopped progression of scoliotic disease.

All the above testifies to the effectiveness of the developed comprehensive program of physical rehabilitation for adolescent girls and allows to recommend it for practical implementation.

The results of re-examination of girls with scoliotic disease demonstrated the effectiveness of the developed rehabilitation program and its advantages over the standard method (table 2).

The scheme shows that the developed comprehensive rehabilitation program is more effective in reducing the angle of spine deviation in comparison with the standard method (fig. 3, 4).

Functional test findings show that the use of static exercises in a comprehensive rehabilitation program increased strength endurance of the back muscles (from the initial $60 \mathrm{sec}$. to $150 \mathrm{sec}$.) and abdominal muscles endurance (from $45 \mathrm{sec}$. to $120 \mathrm{sec}$.), i.e. the formation of a strong muscular core, which is necessary for effective stabilization of the scoliotic process (fig. 5).

In our study, the results of spinal correction using Schroth's method combined with brace therapy were significantly better than those observed after the standard rehabilitation.

Researchers at Columbia University in New York conducted a study of the effect of one yoga exercise (including respiratory technique) on the patients with idiopathic scoliosis. A few months later, a significant clinical effect was observed, which depended on the nature of the disease and the regularity of exercises. The majority of nonsurgical methods of scoliosis treatments are based on changes in the shape of the back and spine as a result of muscle and ligament relaxation. However, these methods have not been sufficiently evaluated in systematic studies. But the authors concluded that asymmetric strengthening of the back muscles on the side of the convex part of the curvature within several months considerably reduces the size of the arch [3]. A common form of rehabilitation for scoliosis is gymnastics according to Lana Paley, which she

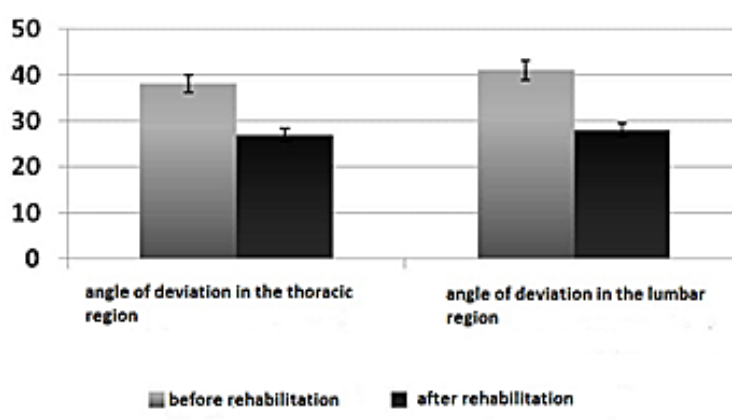

Fig. 3. Main group

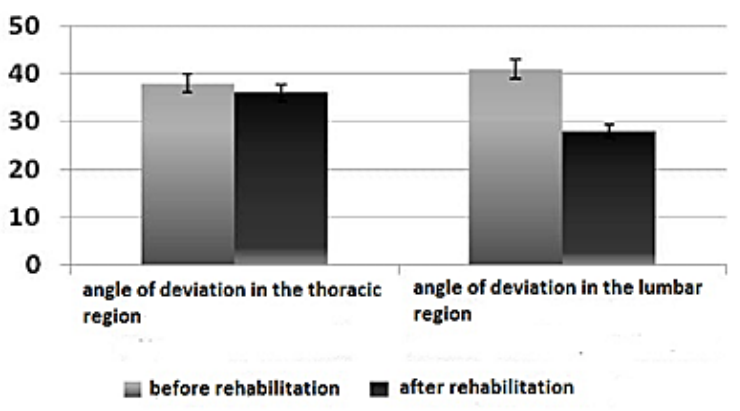

Fig. 4. Control group 
Table 2

Dynamics of clinical and functional parameters in patients from $M G$ and $C G$ under the influence of rehabilitation

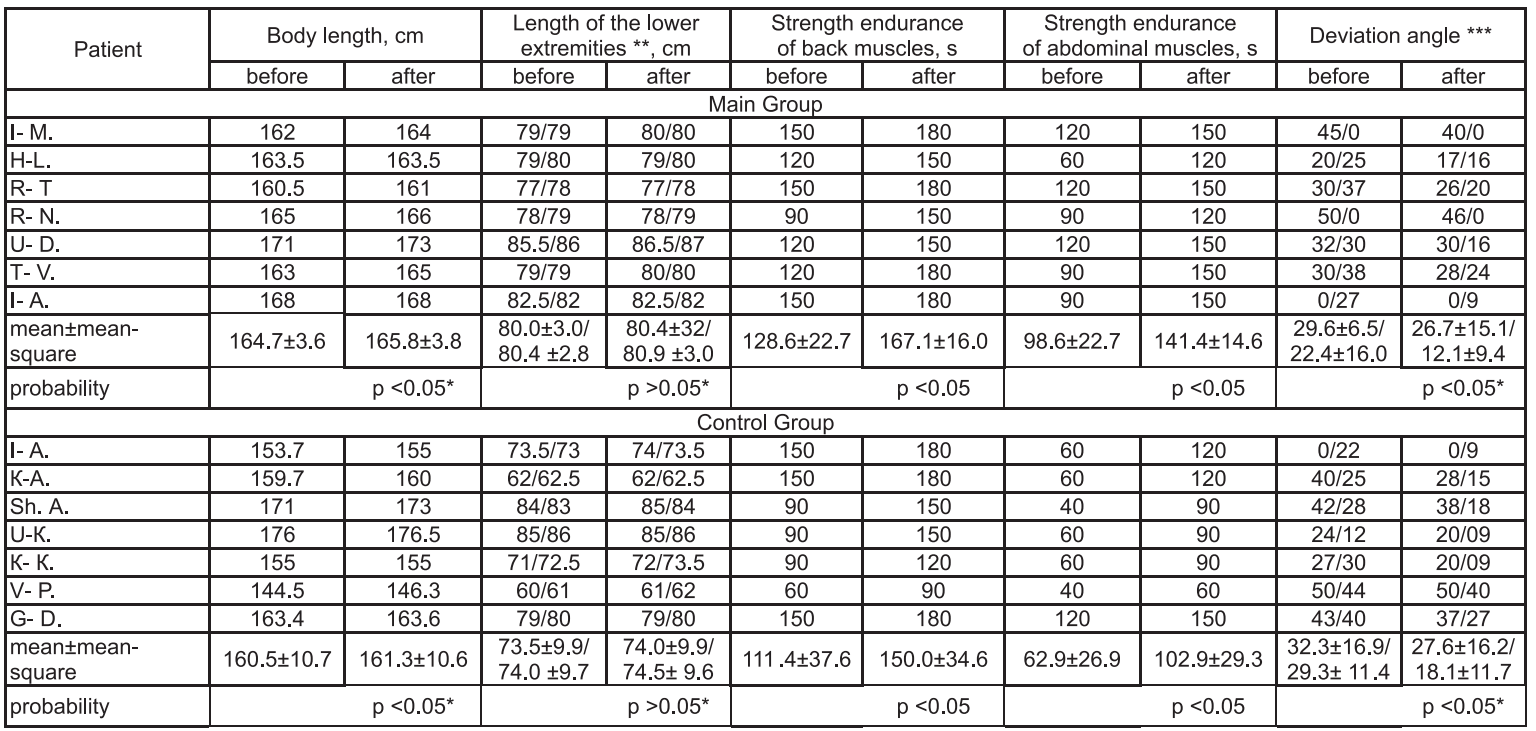

* reliable according to the criteria of Mann-Whitney

** left / right

*** according to Cobb.
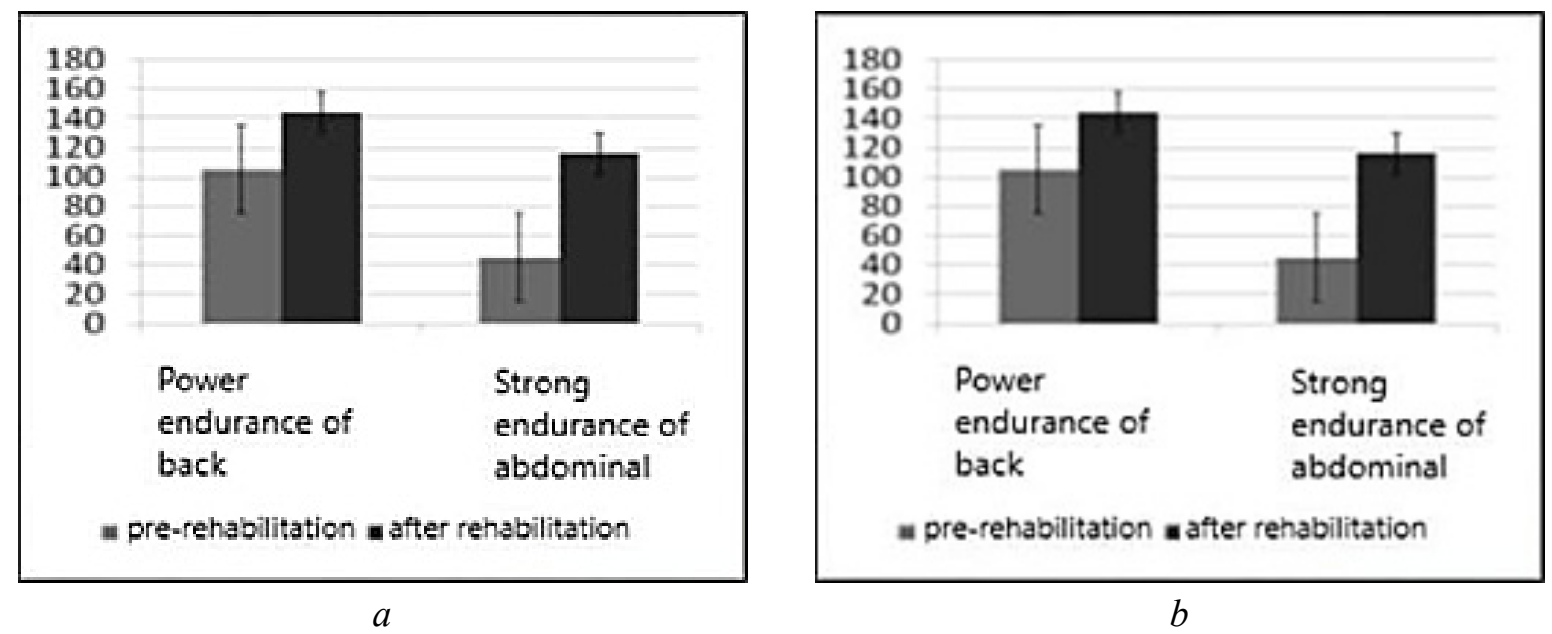

Fig. 5. Comparative characteristics: $a$ - the main group, $b$ - the control group

developed in co-operation with a rheumatologist, P.V. Yevdokimenko. This technique combines strength and stretching exercises, as well as static positions, which are similar to yoga asanas and are performed at a slow pace [10]. Compared to this technique, 3-plane correction exercises seem to be more effective due continuous improvement.

Conclusion

Our findings demonstrate that the use of Schroth's technique in a comprehensive physical rehabilitation program helps to reduce the angle of deviation of the spine better than the conventional technique. It also increases strength endurance of the back and abdominal muscles, promotes formation of a strong muscular core, largely eliminates cosmetic defects. Effective stabilization of the scoliotic process after including Schroth's technique to the original correction method allows recommending it for wide a practical implementation. 


\section{References}

1. Aseyeyva Yu.A., Kolomiets S.I. (2016) The problem of adaptation of children with different degrees of scoliosis No 11 (38) pp 64-68 http://molodyvcheny.in.ua/files/journal/2016/11/15.pd

2. Cheng, J., Castelein, R., Chu, W., Danielsson, A., Dobbs, M., Grivas, T. et al. (2017). 'Adolescent idiopathic scoliosis'. . DOI: 10.1038/nrdp.2015.30

3. Dr. Patrick Bacquaert Sport chez l'Enfant Test de Risser ou bilan radiologique du bassin https:// www.irbms.com/test-de-risser/

4. Fusco C., F. Zaina, S. Atanasio, M. Romano, A. Negrini, S. Negrini (2018). Physical exercises in the treatment of adolescent idiopathic scoliosis: an updated systematic review / Physiother Theory Pract.; 27:80-114. DOI: 10.3109/09593985.2010.533342

5. Kuroki, H. (2018). Brace treatment for adolescent idiopathic scoliosis. Journal of clinical medicine.; 7(6), 136. DOI: $10.3390 / \mathrm{jcm} 7060136$

6. Lehnert-Schroth C., Grobl P. (2017). Tr?jp?aszczyznowa terapia skolioz. Elsevier Urban\&Partner., 8, 53-96.

7. Lonner, B. S., Ren, Y., Cahill, P. J., Shah, S. A., Betz, R. R., \& Samdani, A. F. (2017). Evolution of surgery for adolescent idiopathic scoliosis over 20 years: have outcomes improved? The Spine Journal.; 16(10), 242. DOI: 10.1097/BRS.0000000000002332

8. Melnyk P.[etc.], (2017). Analysis of the activity of the mother and child protection service in Ukraine:Annual report on the state of health of the population, the sanitary and epidemiological situation and the results of the health care system of Ukraine. Kyiv: Medinform, - 458 p. https://ibrary.gov.ua/ shhorichna-dopovid-pro-stan-zdorov-ya-naselennya-sanitarno-epidemichnu-sytuatsiyu-ta-rezultatydiyalnosti-systemy-ohorony-zdorov-ya-ukrayiny-2017-rik/

9. Negrini S. (2017). Orthopaedic and Rehabilitation treatment of idiopathic scoliosis during growth / S. Negrini, J.P. O'Brien, D. Papadopoulos, M. Rigo, C.H. Rivard, M. Romano, H, Weiss // Scoliosis.; 7 (3), 1-35. DOI: 10.1186/s13013-017-0145-8

10. Odno upragnenie pomoget izbavitsa ot scoliosa [One exercise will help get rid of scoliosis] URL https://health.unian.net/worldnews/999700-odno-uprajnenie-pomojet-izbavitsya-ot-skolioza.html

11. Paley L. (2016). Better than yoga. Gymnastics for every day. M .: Mir i obrazovanie,; 96

12. Park, J.H., Jeon, H.S. \& Park, H.W. (2018).'Efects of the Schroth exercise on idiopathic scoliosis: A meta-analysis', European Journal of Physical and Rehabilitation Medicine.; 54(3). DOI: 10.23736/ S1973-9087.17.04461-6

13. Schroth CL. Three-Dimensional Tratment for Scoliosis: A Physiotherapeutic Method for Deformities of the Spine / CL. Schroth, P.T. $7^{\text {th }}$ edition ISBN 978-O-914959-02-1

14. SOSORT Award Winner" / S Schreiber, EC Parent, EK Moez // Scoliosis. (2017). The effect of Schroth exercises added to the standard of care on the quality of life and muscle endurance in adolescents with idiopathic scoliosis-an assessor and statistician blinded randomized controlled trial.. DOI: 10.1186/ s13013-017-0137-8

15. Tyagur T.G. (2014). Scoliosis problem in modern orthopedics - pp 106-108 http://journals.uran.ua/ index.php/1991-0177/issue/view/1423

16. Woznica D.(2018). Terapia skolioz metoda Kathariny Schroth u pacjentow z 389 hipermobilnoscia stawowa. Rehabilitacja w praktyce, 5, 48-52.

Received: 19-Sep-2020

Accepted: 06-Dec-2020 